\title{
JUURNAL.RU
}

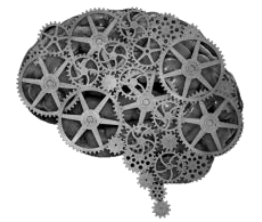

COMPANY GROUP "INTELLEKT"

Реутов В.Е. Крымский федеральный университет имени В.И. Вернадского Симферополь, Россия

doi: 10.18411/lj2016-5-1-15

\section{Роль глобальной регионализации в многополярном мире}

Анализ социально-экономических явлений и процессов, происходящих в мировом геоэкономическом пространстве под влиянием финансового кризиса свидетельствует о смене парадигмы мирового порядка и формирования нового уровня глобальных преобразований. В связи с этим, поиск и обоснование наиболее эффективных механизмов отношений между странами, которые являются лидерами в мировой экономике, а также стран, которые пытаются занять позицию лидера, является актуальным.

Несомненно, что гегемония США в глобализирующемся мире заканчивается. Происходит поступательный процесс создания нового мирового порядка, и формируются новые страны-лидеры в этом процессе. Глобальная экономическая система с несколькими центрами (четыре, пять или шесть) должна прийти на смену существующей системе.

Параллельно с этим, существуют также внутренние интересы, которые объединяют страны друг с другом, как в настоящее время она имеет важное значение для каждой страны, чтобы быть сильным не только в своей внутренней политике, но и быть способной объединить усилия для сотрудничества вокруг взаимных глобальных проблем. Сейчас мы наблюдаем новый глобальный процесс - истернизацию, т.е. расширение прав и усиление влияния Востока.

Она формируется в широком смысле, так как Индия, Китай и Россия являются развитыми странами с развитой экономикой, в конечном итоге и Корея 
и Индонезия может присоединиться к ним. Это приведет к смещению центра тяжести в мировой экономике от Европы и США на Восток. Тем не менее, это не самый важный вопрос. Главное в том, как глобальные экономические центры будут сосуществовать.

Глобализация перейдя в своем развитии на более высокую ступень - этап глобальной регионализации, таким образом, стала одним из наиболее важных тенденций развития современного мира. Таким образом, она действует как интеграция мегарегиональных блоков и проявляется в локализации, границы образования между территориальными и социальными комплексами, возникающих самодостаточных экономических и политических образований, сохранение культурных различий этнических и социальных групп, а также усиление их самоидентичности.

Глобальные процессы регионализации активизируются одновременно на нескольких уровнях: макроуровне, мезоуровне и микроуровне. На макроуровне регионализация проявляется, с одной стороны, в стремлении локальных цивилизаций, чтобы защитить себя от внешнего расширения. Это приводит к так называемому «столкновению цивилизаций», что может стать ключевой проблемой нового мирового порядка. В современном мире, основной конфликт будет происходить между различными типами цивилизаций, так как межцивилизационные различия по своей природе являются фундаментальными.

Регионализация на этом уровне сопровождается тем, что несколько цивилизаций, впитав относительно нейтральную социальную сферу, постепенно очерчивают границы постоянно конфликтогенных зон, так называемых линий «тектонических» разломов в местах столкновения «цивилизационных плит».

Линии разлома между цивилизациями являются будущими линиями фронта. По-видимому, центральной осью мировой политики и в будущем станет экономический конфликт между Западом и остальным миром. Это связано с тем, что Запад пытается навязать свои ценности как универсальные, сохранить военное преимущество и установить свои экономические интересы - все это 
работает на сопротивление. С другой стороны, регионализация на макроуровне проявляется в том, что постиндустриальные страны, будучи инициаторами глобализма, формируют регионализацию, создавая замкнутые и самодостаточные системы. Об этом в частности, свидетельствуют закрытые торговые и инвестиционные потоки в рамках постиндустриальной системы, строгие границ иммиграционной политики на Западе, и т.д. Таким образом, западные страны, закрепив преимущество перед сельскохозяйственными государствами, заинтересованы в сохранении и поддержании их собственной стабильности и независимости.

На мезоуровне глобальная регионализация, которая уже носит наднациональный характер, проявляется в стремлении интеграции некоторых территорий, которые являются и самостоятельными государствами и частью различных стран, например, создание Европейского союза. Другим примером является Азиатско-Тихоокеанский регион (АТР), который включает в себя более чем 40 стран. Здесь создается новый центр мировой экономики и политики.

На микроуровне процессы глобальной регионализации развивались в рамках национальных государств. Здесь районирование связано с усилением разнообразия экономического или политического развития различных территориальных общин в стране, их стремление к культурной независимости, а иногда даже к сепаратизму. В этом контексте регионализация, которая сопровождается экономической и этнокультурной дифференциацией, часто приводит к политическому расщеплению конфликтов и нестабильности в ранее интегрированных государственных образованиях. В контексте глобальных экономических преобразований, ни Китай, ни Россия, ни США ни другие страны не будут полностью доминировать. Скорее всего, будет влияние нескольких сильных стран. Другие страны, такие как Объединенные Арабские Эмираты, также могут присоединиться к ним.

В мире укрепление постбиполярного регионализма сопровождается усилением роли государств, расположенных "на окраине" экономического 
пространства. Там выделяется группа стран, которая эффективно использует эти функции между постсоветскими странами и Западной Европой (Финляндия, Турция, Кипр и т.д.). Финляндия является единственным членом Европейского Союза, который является непосредственным соседом России. Турция и Кипр, расположены на европейской периферии, оказались особенно привлекательным для туризма и в качестве налоговой гавани, соответственно.

Одновременно с этим на всех континентах появляются и укрепляют свое влияние комплексные региональные союзы. Европейский союз (ЕС) и Североамериканское соглашение о свободной торговле (НАФТА) стоят среди них, составляя почти 40\% мирового ВВП. Такие организации, как АзиатскоТихоокеанское экономическое сотрудничество (АТЭС), Ассоциация государств Юго-Восточной Азии, Организация стран экспортеров нефти (ОПЕК) усиливают свое влияние, создаются многие другие региональные альянсы. ЕС и АТЭС лидируют в структуре мирового экспорта среди региональных союзов.

Во второй половине 20-го века удельный вес Азии среди населения планеты увеличилась с 55 до 60\%, в то время как в Европе и Северной Америке это соотношение уменьшилось с 31 до 22\%. За этот период удельный вес Азии в мировом ВВП увеличилась с 17 до 35\%, а Европы и Северной Америки снизился с 72 до 52\%. Изменилась значимость мировых лидеров. Доля населения США снизилась с 6 до 5\%, а в мировом ВВП - с 31 до 21\%. Доля Китая среди населения мира остается на уровне $21 \%$, в то время как его удельный вес в мировом ВВП увеличился с 3 до 10\%.

Конец 20-го века был отмечен значительным усилением позиций в мировой экономике таких региональных интеграционных блоков, как $\mathrm{EC}$, НАФТА, АТЭС, МЕРКОСУР, АСЕАН и т.Д. Они представлены сильными коалициями стран, преследующих свои национальные экономические интересы, предоставление, в первую очередь, благоприятных условий для реализации международного сотрудничества по вопросам регионального масштаба. 
Рост тенденций для усиления позиций региональных союзов стран, усиление межгосударственного регионального сотрудничества и появление региональной формы неравномерности развития мировой экономики определил тот факт, что укрепление финансовой стабильности и ключевых позиций на мировом рынке стали происходить вместе с созданием более широкого экономического пространства.

Для многих регионов этот процесс происходит медленно, хотя регионы получают всё больший вес в мировой экономике в настоящее время. Проблема внутренней и внешней интеграции характерна не только для ЕС. Региональная интеграция является не только консолидацией больших и малых сил, в первую очередь, это наличие сильного положительного эффекта, который будет невозможно реализовать в случае раздельного управления экономикой. Тем не менее, в этом случае общая координация усилий всего сообщества имеет большое значение.

США уже не претендует на господство, в лучшем случае роль этой страны будет как первый среди равных. Большинство американских элит понимают, что мир сегодня совершенно иной. Крайне трудно предвидеть будущее и пути решения ключевых проблем, с которыми сталкивается мировое сообщество в целом или отдельно взятая страна. С развитием глобализации существенное улучшение условий жизни имело место практически во всех странах. Хотя, наиболее впечатляющие результаты были достигнуты в странах с развитой экономикой и лишь в некоторых развивающихся странах.

Увеличение разрыва между доходами в странах с высоким уровнем дохода и стран с низким уровнем дохода, не может не вызывать беспокойства. Кроме того значительное количество населения нашей планеты находится за чертой бедности. Тем не менее, это неправомерно делать вывод, что глобализация является причиной этого, и что ничто не может быть сделано для того, чтобы улучшить эту ситуацию. Напротив, страны с низким уровнем дохода не смогли интегрироваться в мировую экономику так быстро, как другие страны, частично 
из-за выбранной ими политики и факторов, которые невозможно контролировать. Ни одна страна, даже самая бедная, не может позволить себе оставаться изолированной от мировой экономики. В частности, этот способ будет обеспечивать доступ всех людей во всех странах к преимуществам глобализации.

\section{Литература}

1. Абрамов Ю.Ф. "Глобальная регионализация" как предмет теоретикометодологического познания (социально-политический аспект) / Ю.Ф. Абрамов, В.И. Куйбарь // Известия Иркутского государственного университета. Сер. Политология. Религиоведение. - Иркутск, 2007. - Вып. 1. - C. 45-54.

2. Bullon-Cassis L., Towards «Post-Globalization»: Neoliberalism and Global Governance after the Global Financial Crisis // W-2011 [Electronic resources]. URL: http:// www.cris.unu.edu/fileadmin/ working papers/ W-2011-1_new.pdf.

3. Chuzykov V., Global regionalism: History and modern methodology. - K.: KNEU. - 2008. - 272p.

4. Reutov V., Global Regionalization as a Way to Counteraction the Global Financial Threats // Nierówności społeczne a wzrost gospodarczy. - 2013. - N 31. - $\quad$ P. 56-66 [Electronic resources]. URL: http://cejsh.icm.edu.pl/cejsh/element/bwmeta1.element.desklight-68698051197d-4026-b1df-400cbd85c4ea/c/6.pdf 